\title{
Study of the Categorisation Method Using Long-term Measurements
}

\author{
Guillermo REY GOZALO(1),(2), Juan Miguel BARRIGÓN MORILLAS ${ }^{(1)}$, \\ Valentín GÓMEZ ESCOBAR ${ }^{(1)}$, Rosendo VÍLCHEZ-GÓMEZ ${ }^{(1)}$, \\ Juan Antonio MÉNDEZ SIERRA ${ }^{(1)}$, Francisco Javier CARMONA del RÍO(1), \\ Carlos PRIETO GAJARDO ${ }^{(1)}$ \\ (1) Laboratorio de Acústica, Departamento de Física Aplicada, E Politécnica, Universidad de Extremadura \\ Avda. de la Universidad s/n, 10003 Cáceres, Spain; \\ e-mail: \{guille, barrigon, valentin, vilchez, jmendez, jcarmona, carlosprieto\}@unex.es \\ (2) Universidad Autónoma de Chile \\ 5 Poniente 1670, Talca, Región del Maule, Chile; e-mail: greyg@uautonoma.cl
}

(received March 7, 2012; accepted July 15, 2013)

\begin{abstract}
Previous studies concerning the categorisation method have been based on short daytime measurements. These studies demonstrated urban-noise stratification in the daytime. Nevertheless, legislation and standards refer to noise estimation throughout the day. This paper presents the first attempt to apply the categorisation method to indicators obtained through long-term measurements. The study was conducted in Plasencia, Extremadura (Spain) which has approximately 41,500 inhabitants. First, we conducted a stratification of the roads using the categorisation method. Second, long-term measurements (approximately one week) were conducted at different sampling locations across different categories of streets. The results were analysed by category. Moreover, the profile of the noise-level variation was analysed during the day. The results revealed a stratification of sound levels measured across the different categories. Furthermore, we found health risks due to the noise levels in this town. Short-term measurements were also conducted to complete the categorisation method suitability analysis.
\end{abstract}

Keywords: noise pollution, sampling methods, street categorisation.

\section{Introduction}

Noise pollution is an environmental problem present everywhere in developed society. Numerous publications alert us to the dangerous effects of noise (EEA, 2009; WHO, 2011).

Within concern for noise pollution, European legislation demands Member States to elaborate noise maps in population centres with more than 100,000 inhabitants (EU, 2002). Nevertheless, many Europeans live in small towns; thus, they are excluded from these studies. For example, in 2010, $60.2 \%$ of the Spanish population lived in towns with less than 100,000 inhabitants (INE, 2010).

The large percentage of people living in small towns makes devoting effort to these places necessary. For the current studies, our research group used a categorisation method to classify streets into different groups based on their use as communication routes. This in situ method has shown potential as a simpler and less resource-consuming method than gridbased experimental designs. Furthermore, it has revealed promising results in small (REY GOZALO et al., 2012) and medium-sized towns (BARRIGón MORILLAS et al., 2002; 2005a; 2005b; CARMONA DEL RÍO et al., 2011). Recent publications have shown other applications using this methodology (BARRIGón MORILlAs et al., 2010; REY GOZALO et al., 2013), and it has been compared with other in situ methodologies (BARRIGón Morillas et al., 2011).

Our previous studies have been based on short-term measurements from which we estimated sound levels during the day $\left(L_{\mathrm{d}}\right)$. However, the present study analyses, for the first time, the suitability of the categorisation definition by conducting long-term measurements to obtain the $L_{\mathrm{d}}, L_{\mathrm{e}}, L_{\mathrm{n}}$, and $L_{\mathrm{den}}$ indices. Besides, 
relationships among short-term and long-term results are also analysed.

The main objective of this work was to study the performance of the categorisation method and the behaviour of city sound levels using long-term measurements (for approximately one week).

Besides, as a secondary objective, we analyse the acoustical situation of a small city in relation with international reference values.

\section{Methods}

\subsection{Plasencia}

Plasencia has a population of 41,500 inhabitants and is located in the north of the Extremadura region in south-western Spain. Despite its number of inhabitants, Plasencia is the second most populated town in the province and the fourth most populous in the region. The city's economy is based primarily on the trade and services sector which represents $68.3 \%$ of the employed population. It also contributes to the construction and industry sectors $(19.3 \%$ and $8.7 \%$ of the employed population, respectively). The industry sector specialises in agricultural products. For over eight centuries, this village remained locked in a walled area and contact with the outside was conducted through doors and wall shutters. During the nineteenth century, the city grew outside the wall, primarily beside the Jerte River. As a consequence of this history (i.e. excessively narrow and elongated streets), there are problems with modern urban mobility.

\subsection{Categorisation method}

The categorisation method is based on the widely accepted assumption that road traffic is the primary source of noise in most streets. The category definitions used in the present study are the same as in a previous work (BARRIGón MORILlAs et al., 2005a). A summary of the steps needed to apply this method can also be found in this publication.

\subsection{Street categorisation}

The town categorisation consisted in classifying each street into one of six categories. This step required approximately one week: one to two days of study using a map and the assistance of one of the town's residents, and four to five days of in situ study.

The final categorisation of Plasencia is shown in Fig. 1. Only streets with housing were considered. All streets other than pedestrian, restricted-access, and so on not included in Categories 1 to 4 were included in Category 5 .

\subsection{Sampling point selection}

Two types of measurements were conducted for the present study: short-term measurements and longterm measurements.

For the short-term measurements, once every street of the city had been assigned to one of five categories, ten sampling points were randomly selected in each category. Two methods were used: one for Categories 1 to 4 streets and the other for Category 5 streets. In the

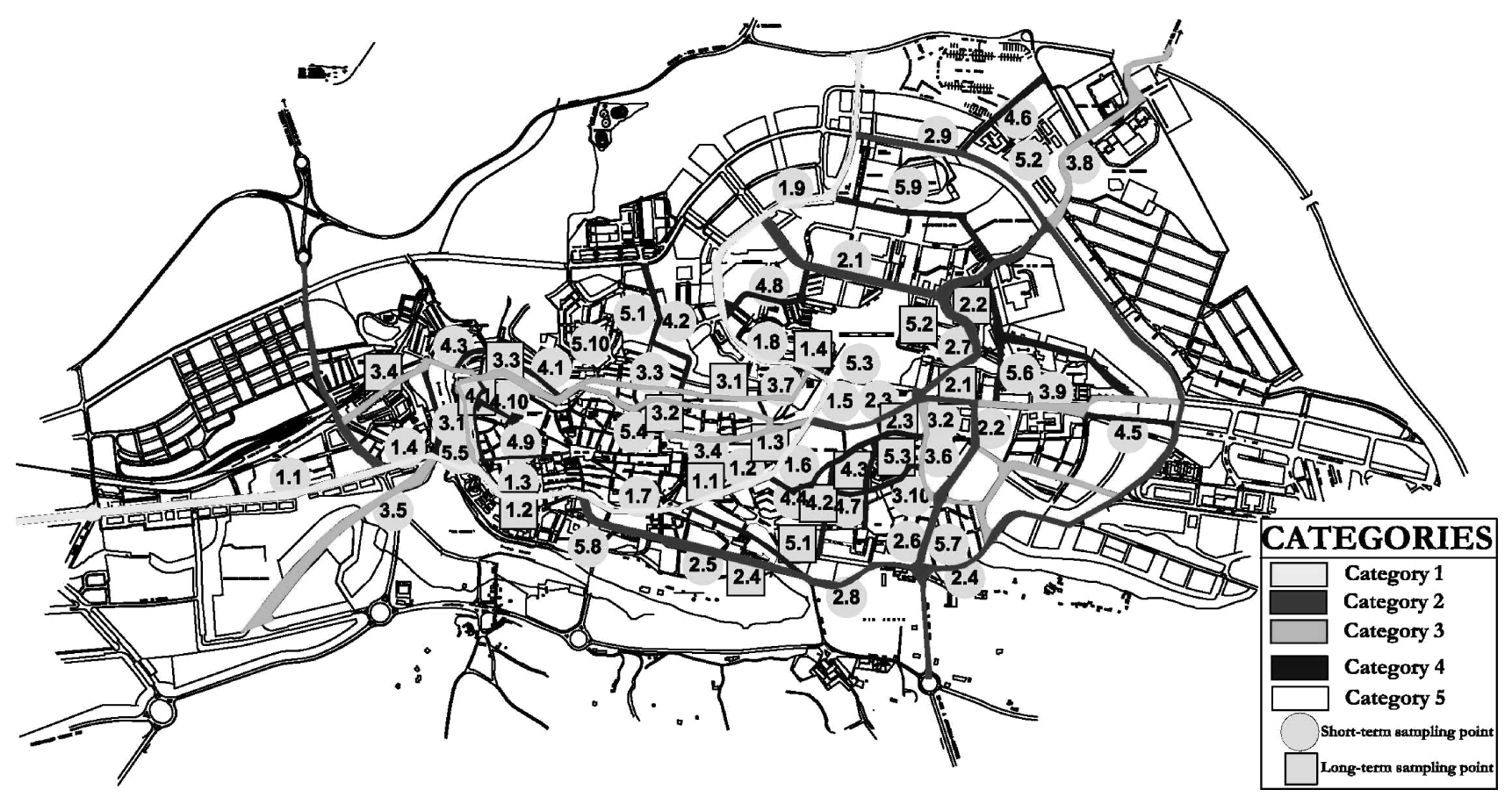

Fig. 1. Map of Plasencia including the different categories and sampling points with both shortand long-term measurements. 
former method, the total length of streets that belonged to each category was calculated and denoted by $L_{i}$, the length of category $i(i=1, \ldots, 4)$. Ten sampling points were located randomly between 0 and $L_{i}$. The only restriction was that equivalent points (i.e., those located on the same street section with no intersection between them) were avoided; thus, only 9 sampling points for Categories 1 and 2 were chosen because it was impossible to select more non-equivalent points. Another random strategy was used in the latter method due to the large number of streets involved in Category $5\left(n_{5}\right)$. Each street was taken as a single potential sampling point $\left(p_{i}, i=1, \ldots, n_{5}\right)$ and ten sampling point selected randomly between 1 and $n_{5}$ and located in the middle of the segment that corresponded to the entire street. Locations of the 48 shortterm measurement points are shown in Fig. 1 and are superimposed on the street categorisation.

For the long-term measurements, several nonequivalent points were selected for each of the categories to locate the maximum number of sampling points. Special care was taken when selecting these points to assure the security of the monitoring equipment with respect to adverse weather conditions and vandalism. The locations of the 18 long-term measurement locations are presented in Fig. 1.

Importantly, the categories do not have a standard size. Thus, to obtain average values for the entire city, each category was weighted by length. Table 1 shows the number of points measured in each category as well as the length percentage and the proportion of the population that lives in each category.

Table 1. The number of sampling points measured for each category. The percentage of each category's street length is determined with respect to the total street length of Plasencia and in proportion to the population that lives in each category.

\begin{tabular}{|l|c|c|c|c|c|}
\hline Category & 1 & 2 & 3 & 4 & 5 \\
\hline $\begin{array}{l}\text { Number of long-term } \\
\text { measurements }\end{array}$ & 4 & 4 & 4 & 3 & 3 \\
\hline $\begin{array}{l}\text { Number of short-term } \\
\text { measurements }\end{array}$ & 9 & 9 & 10 & 10 & 10 \\
\hline \% Length & 5.2 & 8.0 & 5.9 & 10.6 & 70.3 \\
\hline \% Population & 2.1 & 3.5 & 4.9 & 8.7 & 80.8 \\
\hline
\end{tabular}

\subsection{Measurement equipment and procedure}

In-situ noise short-term measurements were made from Monday to Friday in the daytime. Daytime was defined by the European Directive 20002/49/EC (COM, 2002) as from 7:00 a.m. to 7:00 p.m. This period was divided into four 3 -hour periods and one noise measurement of 15 minutes of duration was carried out in each period to obtain a set of four independent measurements for each sampling point. Using this method, only one measurement was performed at each location per day and never during the same time interval.

All measurements were conducted following the ISO 1996-2 guidelines (ISO 1996-2, 2007) using 2260 and 2238 Brüel \& Kjær Type-1 sound level meters equipped with a tripod and a windshield. For the longterm measurements, a 2-metre extension pole separated the microphone from the building facade. For the short-term measurements, the sound level meter was located at a height of 1.5 metres and one metre from the curb. Calibration was performed using a 4231 Brüel \& Kjær calibrator twice a day. The measurement lasted for approximately a week for the long-term measurements.

\section{Results and discussion}

\subsection{Preliminary analysis of long-term measurements}

In the first step, long-term measurements values were normalised to the reference height of 4 metres (EU, 2002). For these calculations, the normalisation effects of geometric divergence for open profile streets (considering streets as a source of line noise) were considered, whereas the French Standard Guide du Bruit corrected the data from streets with a U-shape (CETUR, 1980). Variation of long-term measurements values during a week are shown in Fig. 2 for four sampling points.

In the second step, due to the significant differences between the sound levels of the different categories found in previous studies for short-term measurements (BARRIGón MORILLAS et al., 2005a), we decided to use the long-term measurements to analyse the sound level during a full week to search for similarities, tendencies, differences among categories, and so on. For instance, we analysed the difference between the temporal structure of noise levels in each category in order to check if this structure was similar in all the categories or if, as it happens with noise values, there were differences between categories. For this purpose, we used continuous partial trend models (ToMÉ, MirAndA, 2005a; 2005b). This technique allows for a multiple linear fit by fitting least-squares continuous line segments to a continuous series with a minimum mean square error. After observing the sound-pressure profile of the long-term measurements (Fig. 2) and adjusting calculations with regard to 3,4 , and 5 breakpoints, we decided to analyse each day independently using 3 breakpoints. Table 2 presents the average values of the different breakpoints and the slopes of the lines that join these points for each category.

Considering the time at which a breakpoint first occurs, we are able to observe similar behaviours for the different categories:

- Workdays: The first breakpoint occurs from 4:005:00 a.m., which coincides with the start of city 

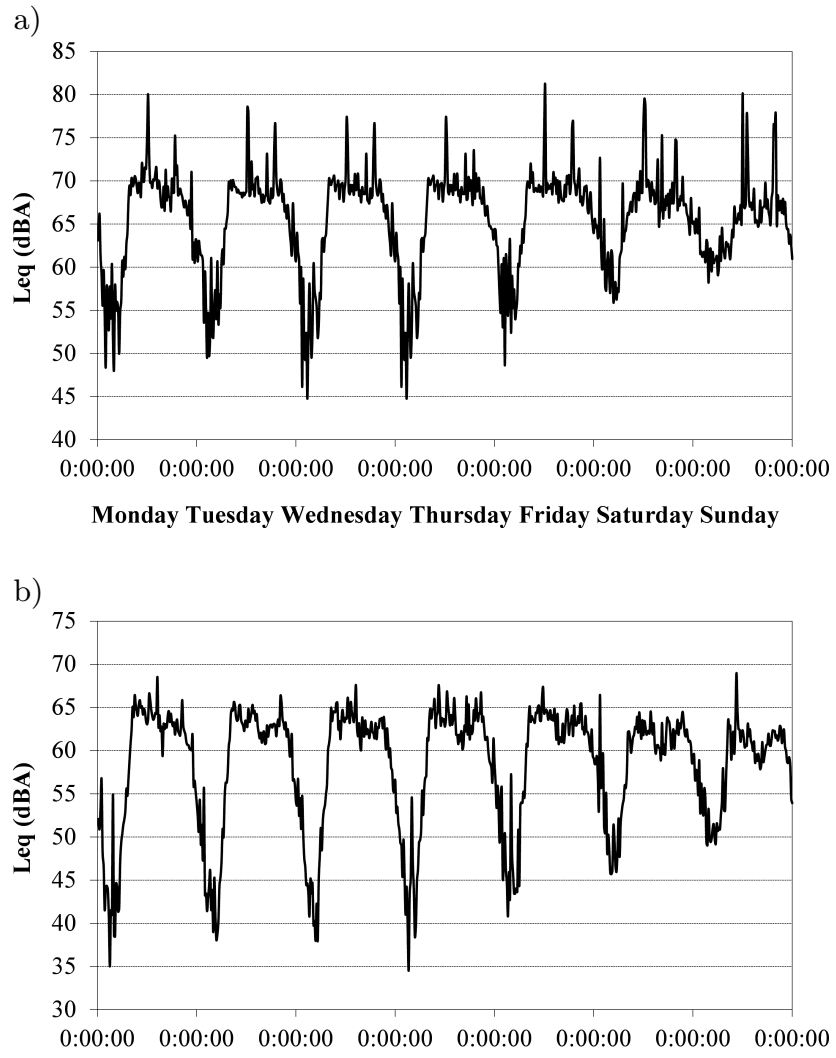

Monday Tuesday Wednesday Thursday Friday Saturday Sunday

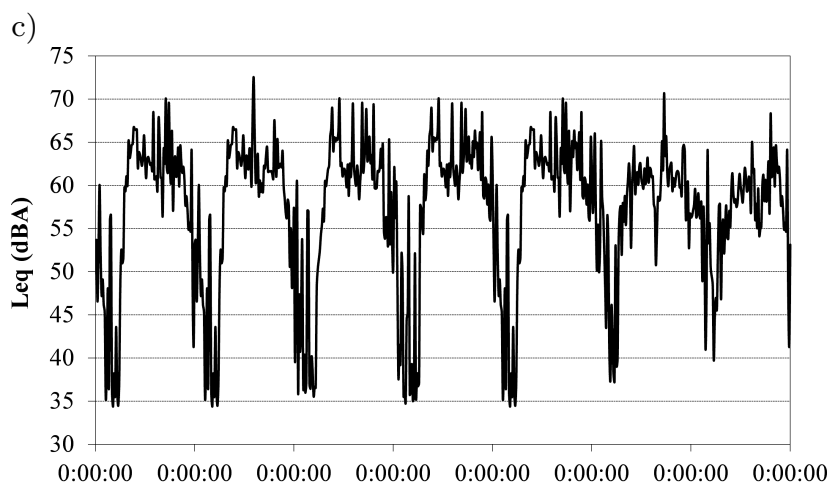

Monday Tuesday Wednesday Thursday Friday Saturday Sunday

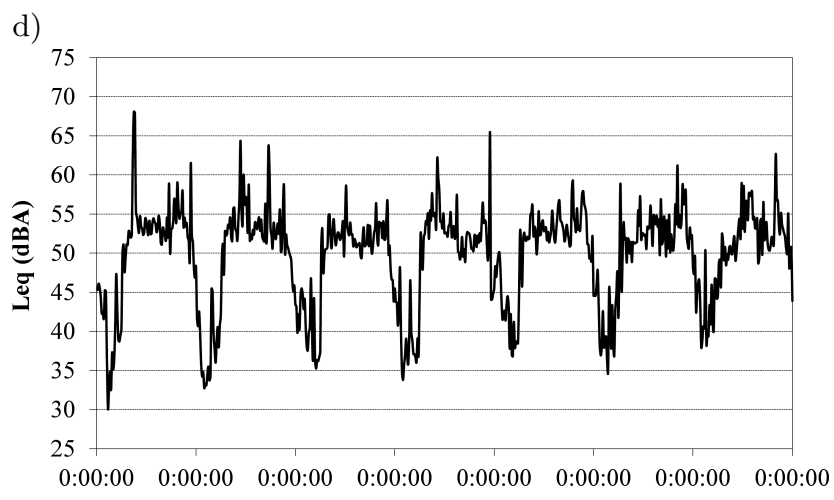

Monday Tuesday Wednesday Thursday Friday Saturday Sunday

Fig. 2. The weeklong variation of $L_{\mathrm{eq}}, 15 \mathrm{~min}$ for some long-term sampling points: a) Point 1.01; b) Point 2.01; c) Point 4.01; and d) Point 5.01.
Table 2. Average breakpoints and slopes calculated from continuous partial trend models.

\begin{tabular}{|c|c|c|c|c|c|}
\hline \multirow{2}{*}{ Category } & \multirow{2}{*}{ Day } & \multicolumn{2}{|c|}{ Breakpoint } & \multicolumn{2}{|c|}{ Slope } \\
\hline & & Code & Finish hour & Code & Value \\
\hline \multirow{6}{*}{1} & \multirow{3}{*}{ Workdays } & 1 & 4 & 1 & -2.48 \\
\hline & & 2 & 9 & 2 & 4.06 \\
\hline & & 3 & 22 & 3 & -0.07 \\
\hline & \multirow{3}{*}{ Weekend } & 1 & 6 & 1 & -1.84 \\
\hline & & 2 & 11 & 2 & 1.92 \\
\hline & & 3 & 23 & 3 & -0.12 \\
\hline \multirow{6}{*}{2} & \multirow{3}{*}{ Workdays } & 1 & 5 & 1 & -2.86 \\
\hline & & 2 & 9 & 2 & 4.71 \\
\hline & & 3 & 22 & 3 & -0.16 \\
\hline & \multirow{3}{*}{ Weekend } & 1 & 6 & 1 & -2.83 \\
\hline & & 2 & 10 & 2 & 2.63 \\
\hline & & 3 & 23 & 3 & 0.11 \\
\hline \multirow{6}{*}{3} & \multirow{3}{*}{ Workdays } & 1 & 5 & 1 & -2.76 \\
\hline & & 2 & 9 & 2 & 4.95 \\
\hline & & 3 & 22 & 3 & 0.01 \\
\hline & \multirow{3}{*}{ Weekend } & 1 & 5 & 1 & -2.36 \\
\hline & & 2 & 11 & 2 & 1.68 \\
\hline & & 3 & 23 & 3 & 0.05 \\
\hline \multirow{6}{*}{4} & \multirow{3}{*}{ Workdays } & 1 & 5 & 1 & -2.51 \\
\hline & & 2 & 9 & 2 & 5.52 \\
\hline & & 3 & 22 & 3 & -0.06 \\
\hline & \multirow{3}{*}{ Weekend } & 1 & 6 & 1 & -2.83 \\
\hline & & 2 & 10 & 2 & 2.61 \\
\hline & & 3 & 22 & 3 & 0.07 \\
\hline \multirow{6}{*}{5} & \multirow{3}{*}{ Workdays } & 1 & 5 & 1 & -2.47 \\
\hline & & 2 & 8 & 2 & 6.25 \\
\hline & & 3 & 22 & 3 & -0.14 \\
\hline & \multirow{3}{*}{ Weekend } & 1 & 5 & 1 & -2.26 \\
\hline & & 2 & 9 & 2 & 3.68 \\
\hline & & 3 & 23 & 3 & 0.05 \\
\hline
\end{tabular}

traffic (i.e. garbage trucks, the first human movements, and so on). The second breakpoint occurs from 8:00-9:00 a.m. when noise levels begin to rise. The third breakpoint occurs at 10:00 p.m. when sound levels stabilise and begin to decrease.

- Weekend: Human activity began later; thus, the first breakpoint is approximately at 5:00-6:00 a.m. Noise levels begin to rise at 10:00-11:00 a.m. (except in Category 5 in which noise rises at 9:00 a.m.). Finally, sound levels stabilise and start to decrease at 10:00-11:00 p.m.

Therefore, there were no important differences between the studied categories; however, we observed differences between workdays and weekend with respect to the breakpoints. Specifically, the first breakpoint oc- 
curs one to two hours later than in working days than weekends.

Then, considering the slope of the lines that join the breakpoints:

- Without considering the category, the slopes of Lines 1 (a reduction in noise levels from 10:0011:00 p.m. to 4:00-6:00 a.m.) and 2 (an increase in noise levels from 4:00-6:00 a.m. to 8:00-11:00 a.m.) are more pronounced in workdays than weekends, whereas there was no difference with regard to the slope of Line 3 . Line 3 has a slope value close to zero because the sound levels are approximately stable between 9:00 a.m. and 10:00 p.m.

- Comparing the slope means of the lines representing different categories, the slopes of Lines 1 and 3 do not differ across the different categories. Nevertheless, the slope of Line 2 increases when the category increases, especially on workdays.

Thus, the sound level variation profiles of the different categories have many similarities to each other during the day. In any case, according to our long-term measurements, the slope that corresponds to the increase of sound levels from the morning (between 4:00 and 6:00 a.m.) to the evening (between 8:00 and 10:00 p.m.) increases with the street category. This finding might indicate other differences between the categories that should be investigated in the future.

Finally, the $L_{\mathrm{d}}, L_{\mathrm{e}}, L_{\mathrm{n}}$, and $L_{\mathrm{den}}$ long-term measurement indices were calculated for each category (Table 3 presents these values). Two indices were calculated for $L_{\mathrm{d}}: L_{\mathrm{d} 12}$ was calculated from 7:00 a.m. to 7:00 p.m., and $L_{\mathrm{d} 16}$ was calculated from 7:00 a.m. to 11:00 p.m. Thus, considering the international reference values (e.g. $65 \mathrm{dBA}, 55 \mathrm{dBA}$, or $45 \mathrm{dBA}$ ) and the average sonorous values for each category (Table 3 ), only the Category $5 L_{\mathrm{d} 16}$ was under $55 \mathrm{dBA}$, a level that the WHO considers as a serious annoyance (WHO, 1999). This represents the $19 \%$ of the population living in this town (see Table 1 ). $L_{\mathrm{d} 16}$ levels above $65 \mathrm{dBA}$ (the value that the OECD suggests as the daytime exposure limit; OECD, 1986) were exceeded by Category 1 and Category 2. At night, the $L_{\mathrm{n}}$ index was under $45 \mathrm{dBA}$ (a value considered by the WHO as a reference value for sleep disturbance; WHO, 1999) at only in workdays in Category 5. Finally, $11 \%$ of the population live in "black acoustic zones" $\left(L_{\mathrm{den}}>65 \mathrm{dBA}\right), 89 \%$ in "grey acoustic zones" $\left(65 \mathrm{dBA}>L_{\text {den }}>55 \mathrm{dBA}\right)$ and $0 \%$ in "white acoustic zones" ( $\left.L_{\text {den }}<55 \mathrm{dBA}\right)$, using the OECD criteria terminology (OECD, 1991).

Therefore, we conclude from the long-term measurement results that Plasencia, despite being a small city, has noise levels that might seriously affect the health and quality of life of a significant percentage of its population, especially at night.
Table 3. Average values of $L_{\mathrm{d} 12}, L_{\mathrm{e}}, L_{\mathrm{d} 16}, L_{\mathrm{n}}$, and $L_{\mathrm{den}}$ indices (in $\mathrm{dBA}$ ) for each category.

\begin{tabular}{|c|c|c|c|c|}
\hline Category & $\begin{array}{l}\text { Sound } \\
\text { Index }\end{array}$ & $\begin{array}{c}\text { Average } \\
\text { value } \\
\text { (workdays) } \\
{[\mathrm{dBA}]} \\
\end{array}$ & $\begin{array}{c}\text { Average } \\
\text { value } \\
\text { (weekend) } \\
{[\mathrm{dBA}]}\end{array}$ & $\begin{array}{c}\text { Average } \\
\text { value } \\
\text { (weekly) } \\
{[\mathrm{dBA}]}\end{array}$ \\
\hline \multirow{5}{*}{1} & $L_{\mathrm{d} 12}$ & $67.7 \pm 2.8$ & $66.0 \pm 3.0$ & $67.3 \pm 2.8$ \\
\hline & $L_{\mathrm{e}}$ & $66.4 \pm 2.1$ & $66.4 \pm 3.1$ & $66.4 \pm 2.3$ \\
\hline & $L_{\mathrm{d} 16}$ & $67.4 \pm 2.6$ & $66.1 \pm 3.1$ & $67.1 \pm 2.7$ \\
\hline & $L_{\mathrm{n}}$ & $58.1 \pm 3.2$ & $61.2 \pm 2.6$ & $59.3 \pm 2.8$ \\
\hline & $L_{\mathrm{den}}$ & $69.4 \pm 2.5$ & $70.2 \pm 2.8$ & $69.7 \pm 2.6$ \\
\hline \multirow{5}{*}{2} & $L_{\mathrm{d} 12}$ & $66.1 \pm 0.8$ & $63.2 \pm 0.9$ & $65.4 \pm 0.8$ \\
\hline & $L_{\mathrm{e}}$ & $64.8 \pm 1.4$ & $64.7 \pm 1.7$ & $64.8 \pm 1.5$ \\
\hline & $L_{\mathrm{d} 16}$ & $65.8 \pm 0.9$ & $63.6 \pm 1.1$ & $65.3 \pm 0.9$ \\
\hline & $L_{\mathrm{n}}$ & $55.3 \pm 1.5$ & $59.2 \pm 1.0$ & $56.8 \pm 1.3$ \\
\hline & $L_{\mathrm{den}}$ & $67.6 \pm 1.1$ & $68.2 \pm 1.2$ & $67.8 \pm 1.1$ \\
\hline \multirow{5}{*}{3} & $L_{\mathrm{d} 12}$ & $63.2 \pm 2.6$ & $60.5 \pm 1.5$ & $62.6 \pm 2.3$ \\
\hline & $L_{\mathrm{e}}$ & $63.4 \pm 2.0$ & $61.7 \pm 1.8$ & $63.0 \pm 1.8$ \\
\hline & $L_{\mathrm{d} 16}$ & $63.2 \pm 2.4$ & $60.9 \pm 1.5$ & $62.7 \pm 2.2$ \\
\hline & $L_{\mathrm{n}}$ & $54.1 \pm 1.8$ & $57.1 \pm 1.3$ & $55.2 \pm 1.5$ \\
\hline & $L_{\mathrm{den}}$ & $65.9 \pm 2.0$ & $65.7 \pm 1.3$ & $65.8 \pm 1.7$ \\
\hline \multirow{5}{*}{4} & $L_{\mathrm{d} 12}$ & $60.5 \pm 2.4$ & $57.9 \pm 1.5$ & $59.9 \pm 2.3$ \\
\hline & $L_{\mathrm{e}}$ & $60.4 \pm 1.4$ & $59.0 \pm 1.6$ & $60.0 \pm 1.5$ \\
\hline & $L_{\mathrm{d} 16}$ & $60.5 \pm 2.1$ & $58.2 \pm 1.5$ & $60.0 \pm 1.9$ \\
\hline & $L_{\mathrm{n}}$ & $50.8 \pm 1.5$ & $53.0 \pm 3.1$ & $51.6 \pm 2.1$ \\
\hline & $L_{\mathrm{den}}$ & $62.9 \pm 1.5$ & $62.3 \pm 2.1$ & $62.7 \pm 1.7$ \\
\hline \multirow{5}{*}{5} & $L_{\mathrm{d} 12}$ & $53.6 \pm 0.5$ & $50.8 \pm 1.1$ & $53.0 \pm 0.4$ \\
\hline & $L_{\mathrm{e}}$ & $52.8 \pm 0.8$ & $52.5 \pm 1.7$ & $52.7 \pm 1.0$ \\
\hline & $L_{\mathrm{d} 16}$ & $53.4 \pm 0.3$ & $51.3 \pm 1.3$ & $52.9 \pm 0.4$ \\
\hline & $L_{\mathrm{n}}$ & $44.5 \pm 3.0$ & $46.2 \pm 0.3$ & $45.2 \pm 2.0$ \\
\hline & $L_{\text {den }}$ & $55.9 \pm 0.6$ & $55.7 \pm 0.9$ & $55.8 \pm 0.5$ \\
\hline
\end{tabular}

\subsection{Analysis of categorisation method}

As shown in Table 3, the long-term measurement average values of all the analysed indices decrease when the number of the category increases. These results seem to indicate the existence of noise-level stratification in the city. Nevertheless, sampling point locations are not similar and obtained values must to be normalised.

Thus, long-term measurements were used to obtain the sound power level per length of traffic source (assuming it is linear). This calculation was necessary to compare the long-term results with the short-term results because different distances to the source must be considered with the reflection effects (ISO 9613-2, 1996). The average power level was evaluated in each category after accounting for these divergence and reflection effects. One order of reflection was considered; reflections on vertical obstacles were treated with the help of image-sources, as used in several national calculation methods (EC, 2003). As shown in Table 4, 
Table 4. Sound power levels $\left(L_{\mathrm{w}}\right.$, in dBA) of the linear traffic source for each category.

\begin{tabular}{|c|c|c|c|c|c|c|c|c|c|}
\hline \multirow[b]{2}{*}{ 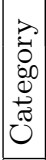 } & \multicolumn{3}{|c|}{$L_{\mathrm{d} 16 \mathrm{w}}[\mathrm{dBA}]$} & \multicolumn{3}{|c|}{$L_{\mathrm{nw}}[\mathrm{dBA}]$} & \multicolumn{3}{|c|}{$L_{\mathrm{d} 24 \mathrm{w}}[\mathrm{dBA}]$} \\
\hline & $\begin{array}{c}\text { Average } \\
\text { value } \\
\text { (workdays) }\end{array}$ & $\begin{array}{c}\text { Average } \\
\text { value } \\
\text { (weekend) }\end{array}$ & $\begin{array}{l}\text { Average } \\
\text { value } \\
\text { (weekly) } \\
\end{array}$ & $\begin{array}{c}\text { Average } \\
\text { value } \\
\text { (workdays) } \\
\end{array}$ & $\begin{array}{c}\text { Average } \\
\text { value } \\
\text { (weekend) }\end{array}$ & $\begin{array}{l}\text { Average } \\
\text { value } \\
\text { (weekly) } \\
\end{array}$ & $\begin{array}{c}\text { Average } \\
\text { value } \\
\text { (workdays) }\end{array}$ & $\begin{array}{c}\text { Average } \\
\text { value } \\
\text { (weekens) }\end{array}$ & $\begin{array}{c}\text { Average } \\
\text { value } \\
\text { (weekly) }\end{array}$ \\
\hline 1 & $81.9 \pm 0.6$ & $80.6 \pm 1.2$ & $81.6 \pm 0.7$ & $72.6 \pm 1.2$ & $75.7 \pm 0.7$ & $73.8 \pm 0.8$ & $80.4 \pm 0.6$ & $79.5 \pm 1.1$ & $80.2 \pm 0.6$ \\
\hline 2 & $80.1 \pm 0.4$ & $77.9 \pm 0.7$ & $79.6 \pm 0.5$ & $69.6 \pm 1.3$ & $73.5 \pm 0.9$ & $71.1 \pm 1.1$ & $78.6 \pm 0.4$ & $76.8 \pm 0.6$ & $78.1 \pm 0.4$ \\
\hline 3 & $76.5 \pm 1.5$ & $74.2 \pm 1.5$ & $76.0 \pm 1.4$ & $67.4 \pm 0.4$ & $70.4 \pm 0.6$ & $68.5 \pm 0.3$ & $75.1 \pm 1.4$ & $73.2 \pm 1.3$ & $74.6 \pm 1.3$ \\
\hline 4 & $73.0 \pm 0.5$ & $70.6 \pm 1.1$ & $72.5 \pm 0.6$ & $63.2 \pm 1.3$ & $65.4 \pm 1.7$ & $64.0 \pm 1.2$ & $71.5 \pm 0.5$ & $69.5 \pm 1.0$ & $71.0 \pm 0.6$ \\
\hline 5 & $66.2 \pm 0.4$ & $64.1 \pm 1.5$ & $65.7 \pm 0.6$ & $57.3 \pm 3.0$ & $59.0 \pm 0.2$ & $58.0 \pm 2.0$ & $64.7 \pm 0.5$ & $62.9 \pm 1.3$ & $64.3 \pm 0.6$ \\
\hline \multirow[b]{2}{*}{ 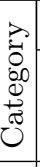 } & \multicolumn{3}{|c|}{$L_{\mathrm{d} 12 \mathrm{w}}[\mathrm{dBA}]$} & \multicolumn{3}{|c|}{$L_{\text {ew }}[\mathrm{dBA}]$} & & & \\
\hline & $\begin{array}{c}\text { Average } \\
\text { value } \\
\text { (workdays) }\end{array}$ & $\begin{array}{c}\text { Average } \\
\text { value } \\
\text { (Weekends) }\end{array}$ & $\begin{array}{l}\text { Average } \\
\text { value } \\
\text { (weekly) }\end{array}$ & $\begin{array}{c}\text { Average } \\
\text { value } \\
\text { (workdays) } \\
\end{array}$ & $\begin{array}{c}\text { Average } \\
\text { value } \\
\text { (Weekends) }\end{array}$ & $\begin{array}{c}\text { Average } \\
\text { value } \\
\text { (weekly) }\end{array}$ & & & \\
\hline 1 & $82.2 \pm 0.7$ & $80.5 \pm 1.2$ & $81.8 \pm 0.8$ & $80.8 \pm 0.4$ & $80.9 \pm 1.3$ & $80.9 \pm 0.4$ & & & \\
\hline 2 & $80.4 \pm 0.4$ & $77.4 \pm 0.6$ & $79.7 \pm 0.3$ & $79.1 \pm 1.0$ & $79.0 \pm 1.3$ & $79.1 \pm 1.0$ & & & \\
\hline 3 & $76.5 \pm 1.7$ & $73.8 \pm 1.3$ & $75.9 \pm 1.6$ & $76.6 \pm 1.0$ & $75.0 \pm 2.2$ & $76.3 \pm 1.0$ & & & \\
\hline 4 & $73.0 \pm 0.2$ & $70.3 \pm 1.0$ & $72.4 \pm 0.2$ & $72.9 \pm 1.8$ & $71.5 \pm 1.3$ & $72.5 \pm 1.7$ & & & \\
\hline 5 & $66.3 \pm 0.6$ & $63.6 \pm 1.3$ & $65.7 \pm 0.6$ & $65.5 \pm 0.9$ & $65.2 \pm 1.9$ & $65.5 \pm 1.2$ & & & \\
\hline
\end{tabular}

the sound power levels decrease when the category number increases, and there is practically no overlap. Table 4 clearly shows the existence of noise stratification in all of the time periods considered across the city. In addition, these results indicate that the categorisation method suitably characterises the noise stratification in the city. Nevertheless, the long-term measurements cannot statistically demonstrate that the categorisation method suitably discriminates this stratification due to the small number of sampling points (a maximum of four points per category). Thus, the existence of the mentioned stratification will be analysed using the results of the short-term measurements and checking the coherence among short-term and long-term results.

Short-term measurements allowed us to obtain a dataset large enough to statistically examine the possible differences between the measured sound levels. In previous studies, approximately 10 sampling points per category were sufficient to analyse the differences between five categories (BARRIGón Morillas et al., 2002; 2005a; 2011). Thus, as previously mentioned, 9-10 points were selected in Plasencia per category (see Table 1) to characterise the noise of the city that was not examined with the long-term measurements.

Table 5 shows the average $L_{\text {eq }}$ values obtained for each category for short-term measurements and average sound power levels calculated both from short-term and long-term measurements (the latter being previously shown in Table 4 ). $L_{\text {eq }}$ values were obtained as the arithmetic mean of the sound level values of the points of each category. Sound power per unit length values for short-term measurements were obtained as the arithmetic mean of the power values of the dif- ferent points which were obtained from the measured sound pressure levels with the same calculation procedure used for long-term measurements.

Table 5. $L_{\mathrm{d} 12 \mathrm{~h}}$ and sound power levels obtained for shortterm measurements. The $L_{\mathrm{d} 12 \mathrm{w}}$ obtained for workdays is also shown.

\begin{tabular}{|c|c|c|c|}
\hline 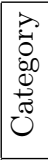 & $\begin{array}{c}L_{\mathrm{d} 12}[\mathrm{dBA}] \\
\text { Workdays } \\
\text { Short-term } \\
\text { measurements }\end{array}$ & $\begin{array}{c}L_{\mathrm{d} 12 \mathrm{w}}[\mathrm{dBA}] \\
\text { Workdays } \\
\text { Short-term } \\
\text { measurements }\end{array}$ & $\begin{array}{c}L_{\mathrm{d} 12 \mathrm{w}}[\mathrm{dBA}] \\
\text { Workdays } \\
\text { Long-term } \\
\text { measurements }\end{array}$ \\
\hline 1 & $71.5 \pm 0.8$ & $81.6 \pm 0.8$ & $82.2 \pm 0.7$ \\
\hline 2 & $69.5 \pm 0.8$ & $79.9 \pm 0.7$ & $80.4 \pm 0.4$ \\
\hline 3 & $67.1 \pm 1.5$ & $77.0 \pm 1.2$ & $76.5 \pm 1.7$ \\
\hline 4 & $64.7 \pm 1.3$ & $73.3 \pm 2.5$ & $73.0 \pm 0.2$ \\
\hline 5 & $59.7 \pm 3.2$ & $68.1 \pm 3.3$ & $66.3 \pm 0.6$ \\
\hline
\end{tabular}

As can be seen in Table 5, sound power values are similar between short-term measurements and longterm measurements. These results indicate that, when averaging by category, short-term sound levels provide a sufficient approximation of the weekly sound levels in daytime period.

We performed a statistical analysis of the sound power values obtained from the street to examine the differences in sound power levels among the five categories. We sought to determine whether these differences were significant at a $95 \%$ confidence interval.

We proposed the following hypotheses for the analysis below:

- $H_{0}=$ There were no significant differences among the sound power level means of the different categories. 
- $H_{1}=$ There were significant differences among the sound power level means of the different categories.

Before conducting the appropriate statistical test to address the hypotheses, we analysed the normality of the data using the Shapiro-Wilk test (SHAPIRO, 1965). We obtained a $p$-value of 0.0072 , indicating that these data significantly differed from a normal distribution. This lack of normality, together with the small number of data in each category, suggests the use of nonparametric tests because the results are less disputable.

Thus, we first analysed the different categories using the Kruskal-Wallis test (KRUSKAL, WALLIS, 1952). We obtained a $p$-value of $1.037 \cdot 10^{-8}$ which indicates a significant difference among the categories. Then, we used the Mann-Whitney $U$ test with a Bonferroni correction to perform multiple comparisons between different category pairs (MANN, WHITNEY, 1947; MARTin, Altman, 1995). The results of this test are shown in Table 6 .

As shown in Table 6, there were differences between all category pairs at a significance level less than or equal to 0.05 . Thus, the categorisation method is a suitable method of studying the noise stratification in small cities.

As a second proof of this suitability, we used the ROC analysis (HAND, TILL, 2001; FAWCETT, 2006) to demonstrate the predictive capacity of this method. ROC has been previously and successfully used to support similar aims (CARMONA del Río et al., 2011). Ta- ble 7 shows the results of this analysis. As can be seen, the marks of the strata were close to the means of all categories. This proximity is indicative of the internal coherence of the category method.

ROC analysis sensitivity is a measure of the capacity to include the previously assigned streets in the stratum. The results presented in Table 7 are encouraging: the sensitivity was $100 \%$ in Stratum 1, and $70 \%$ or greater in the other strata. Consequently, the overall sensitivity of the method was over $85 \%$ : of a group of five streets, four presented sound values that corresponded to the stratum to which they were assigned in the initial categorisation (prior to measurement).

The nonspecificity measures the proportion of streets that were not initially assigned to a certain stratum but for which the ROC analysis indicates that they belong to that stratum. As shown in Table 7, only Strata 4 and 5 revealed a nonspecificity greater than $5 \%$. These values were less than $3 \%$ for the rest of the strata. The overall nonspecificity was $14.6 \%$ which is consistent with the overall sensitivity. This result means that, on average, the ROC analysis assigned less than one of the five streets to a stratum that was different from the one to which the categorisation method had assigned it.

Finally, the predictive values of the different strata represent the proportion of the streets that the ROC analysis assigned to the stratum that matched the categories to which they were initially assigned, relative

Table 6. Mann-Whitney $U$ test results with a Bonferroni correction: $\left({ }^{* *}\right) p<0.001,\left({ }^{* *}\right) p<0.01$, and $\left(^{*}\right) p<0.05$.

\begin{tabular}{|c|c|c|c|c|c|}
\hline \multirow{6}{*}{ 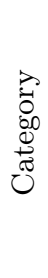 } & & \multicolumn{4}{|c|}{ Category } \\
\hline & & 1 & 2 & 3 & 4 \\
\hline & 2 & $0.00288(* *)$ & - & - & - \\
\hline & 3 & $0.00022(* * *)$ & $0.00152(* *)$ & - & - \\
\hline & 4 & $0.00022(* * *)$ & $0.00022(* * *)$ & $0.00325(* *)$ & - \\
\hline & 5 & $0.00022(* * *)$ & $0.00022(* * *)$ & $0.00011(* * *)$ & $0.01505\left(^{*}\right)$ \\
\hline
\end{tabular}

Table 7. ROC analysis results.

\begin{tabular}{|l|c|c|c|c|c|c|c|c|c|c|}
\hline \multicolumn{1}{|c|}{ Stratum } & 1 & & 2 & & 3 & & 4 & & 5 & all \\
\hline Mark & 81.5 & & 79.4 & & 77.1 & & 73.9 & & 66.9 & \\
\hline Upper limit & 82.5 & & 80.4 & & 78.3 & & 75.8 & & 72.0 & \\
\hline Lower limit & 80.4 & & 78.3 & & 75.8 & & 72.0 & & 61.8 & \\
\hline Amplitude & 2.1 & & 2.1 & & 2.6 & & 3.8 & & 10.2 & \\
\hline AUC & & 0.96 & & 0.96 & & 0.94 & & 0.90 & & \\
\hline Sensitivity (n $\left.{ }^{\circ}\right)$ & 9 & & 8 & & 8 & & 7 & & 9 & 41 \\
\hline Sensitivity (\%) & 100 & & 88.9 & & 80.0 & & 70.0 & & 90.0 & 85.4 \\
\hline Nonspecificity $\left(\mathrm{n}^{\circ}\right)$ & 1 & & 1 & & 1 & & 2 & & 2 & 7 \\
\hline Nonspecificity (\%) & 2.6 & & 2.6 & & 2.6 & & 5.3 & & 5.3 & 14.6 \\
\hline Predictive value (\%) & 90.0 & & 88.9 & & 88.9 & & 77.8 & & 81.8 & 85.4 \\
\hline
\end{tabular}


to the total number of streets that the ROC analysis determined for the stratum. Table 7 shows that, except for Stratum 4, the predictive values were greater than $80 \%$. The overall predictive value was $85 \%$.

\section{Conclusions}

The primary conclusions of the present study are as follows:

- Considering that linear noise sources are similar for short and long-term measurements, the sound power levels in the daytime indicate that short-term measurements are sufficient when an adequate number of long-term measurements cannot be conducted.

- Significant short-term measurement differences were found among the different categories with regard to sound levels in the streets. This finding demonstrates the effectiveness of the categorisation method.

- We found a clear differentiation among the different categories with regard to the indices calculated from the long-term measurements.

From these conclusions, we surmise that the categorisation method can be expected to sufficiently estimate the long-term indicators recommended in the European Directive. Nevertheless, more studies are necessary to confirm this conclusion.

- We found that sound level variation behaves similarly throughout the day across the different categories. This finding implies that the city's sound is homogeneous across locations.

- The ROC analysis that examined the predictive capacity of the categorisation method in Plasencia found overall sensitivities and predictive values higher than $85 \%$ with regard to the categorisation method.

\section{Acknowledgments}

The University of Extremadura (Acción III. Plan Iniciación a la Investigación, Desarrollo Tecnológico e Innovación 2011), the European Social Fund, the European Regional Development Fund (ERDF), and Junta de Extremadura (Projects PRI06A271, PD10166, and GR10175), Consejería de Economía, Comercio e Innovación supported this work.

\section{References}

1. BARrigón Morillas J.M., Gómez Escobar V., MÉndez Sierra J.A., Vílchez-Gómez R., Trujillo Carmona J. (2002), An environmental noise study in the city of Cáceres, Spain, Appl. Acoust., 63, 10611070.
2. BARrigón Morillas J.M., Gómez Escobar V., MÉndez Sierra J.A., Vílchez-Gómez R., VAquero J.M., Trujillo Carmona J. (2005a), A categorization method applied to the study of urban road traffic noise, J. Acoust. Soc. Am., 117, 2844-2852.

3. BARrigón Morillas J.M., GÓMez Escobar V., Vaquero J.M, Méndez Sierra J.A., Vílchez-GóMEZ R. (2005b), Measurements of noise pollution in Badajoz City, Spain, Acta Acustica united with Acustica, 91, 797-801.

4. Barrigón J.M., Gómez Escobar V., Rey Gozalo G., Vílchez-Gómez R. (2010), Possible relation of noise levels in streets to the population of the municipalities in which they are located, J. Acoust. Soc. Am., 128, EL86-EL92.

5. BArrigón Morillas J.M., Gómez Escobar V., MÉndez Sierra J.A., VÍlchez-Gómez R., Carmona del Río J., Trujillo Carmona J. (2011), Comparison of two procedures for the evaluation of urban noise, Appl. Acoust., 71, 760-771.

6. Carmona del Río F.J., Gómez Escobar V., Trujillo Carmona J., Vílchez-Gómez R., MÉndez Sierra J.A., Rey Gozalo G., Barrigón MorilLAS J.M. (2011), Application of a street categorization method to the study of urban noise: the Valladolid (Spain) study, Environmental Engineering Science, 28, 811-817.

7. CETUR, Centre d'Etudes des Transports Urbains (1980), Guide du Bruit des Transports Terrestres. Prévision des niveaux sonores, CETUR, France.

8. EC (European Commision) (2003), Adaptation and revision of the interim noise computation methods for the purpose of strategic noise mapping, European Commision DG Environment, reference: B43040/2001/329750/MAR/C1.

9. EU (European Union) (2002), Directive 2002/49/EC relating to the Assessment and Management of Environmental Noise, Official Journal of the European Communities, No. L 189.

10. Fawcett T. (2006), An introduction to ROC analysis, Pattern Recognition Letters, 27, 861-874.

11. Hand D.J., Till R.J. (2001), A simple generalisation of the area under the ROC curve for multiple class classification problems, Machine Learning, 45, 171-186.

12. INE, Instituto Nacional de Estadística (2010), Padrón municipal: cifras oficiales de población, INE, Madrid.

13. ISO 1996-2: 2007 (2007), Description, measurement and assessment of environmental noise. Part 2: Determination of environmental noise levels, International Organization for Standardization, Switzerland.

14. ISO 9613-2: 1996 (1996), Acoustic-attenuation of sound during propagation outdoors. Part 2: General method of calculation, International Organization for Standardization, Switzerland. 
15. Kruskal W.H., Wallis W.A. (1952), Use of ranks in one-criterion variance analysis, Journal of American Statistical Association, 47, 583-621.

16. Mann H.B., Whitney D.R. (1947), On a test of whether one of two random variables is stochastically larger than the other, Annals of Mathematical Statistics, 18, 50-60.

17. Martin J., Altman D.G. (1995), Statistic notes: Multiple significance test: the Bonferroni method, British Medical Journal, 310, 170.

18. OECD, Organization for Economic Cooperation and Development (1986), Fighting Noise: Strengthening Noise Abatement Policies, OECD Publications, Paris.

19. OECD, Organization for Economic Cooperation and Development (1991), Fighting noise in 1990s, OECD Publications, Paris.

20. Rey Gozalo G., Barrigón Morillas J.M., Gómez ESCOBAR V. (2013), Urban streets functionality as a tool for urban pollution management, Science of the Total Environment, 461-462, 453--461.
21. Rey Gozalo G., Barrigón Morillas J.M., Gómez Escobar V. (2012), Analysis of noise exposure in two small towns, Acta Acustica united with Acustica, 98, 884-893.

22. Shapiro S.S. (1965), An analysis of variance test for normality (complete samples), Biometrika, 52 (3-4), 591-611.

23. Tomé A.R., Miranda P.M.A. (2005a), Continuous partial trends and low-frequency oscillations of time series, Nonlinear Processes in Geophysics, 12, 451-460.

24. Tomé A.R., Miranda P.M.A. (2005b), Large scale spatial structure of observed temperature trends, Proceeding 16th Conference on Climate Variability and Change, American Meteorological Society.

25. WHO, World Health Organization (1999), Guidelines for Community Noise, WHO, Geneva.

26. WHO, World Health Organization (2011), Burden of disease from environmental noise. Quantification of healthy life years lost in Europe, WHO, Geneva. 